\title{
Epidemiological study to investigate potential interaction between physical and psychosocial factors at work that may increase the risk of symptoms of musculoskeletal disorder of the neck and upper limb
}

\author{
J J Devereux, I G Vlachonikolis, P W Buckle
}

Occup Environ Med 2002;59:269-277

See end of article for authors' affiliations

Correspondence to: Dr Jason Devereux, Robens Centre for Health

Ergonomics, European Institute of Health and

Medical Sciences,

University of Surrey,

Guildford, Surrey

GU2 7TE, UK;

J.Devereux@surrey.ac.uk

Accepted

17 October 2001

\begin{abstract}
Objectives: To investigate potential interactions between physical and psychosocial risk factors in the workplace that may be associated with symptoms of musculoskeletal disorder of the neck and upper limb.

Methods: 891 of 1514 manual handlers, delivery drivers, technicians, customer services computer operators, and general office staff reported on physical and psychosocial working conditions and symptoms of neck and upper limb disorders using a self administered questionnaire (59\% return rate). Of the 869 valid questionnaire respondents, 564 workers were classified in to one of four exposure groups: high physical and high psychosocial, high physical and low psychosocial, low physical and high psychosocial, and low physical and low psychosocial. Low physical and low psychosocial was used as an internal reference group. The exposure criteria were derived from the existing epidemiological literature and models for physical and psychosocial work factors. The frequency and amplitude of lifting and the duration spent sitting while experiencing vibration were used as physical exposure criteria. Ordinal values of mental demands, job control, and social support with managers and coworkers were used as psychosocial exposure criteria.

Results: In the multivariate analyses, the highest and significant increase in risk was found in the high physical and high psychosocial exposure group for symptoms of hand or wrist and upper limb disorders after adjusting for years at the job, age, and sex. A potential interaction effect was found for the symptoms of the hand or wrist and upper limb disorders but not for the neck symptoms.

Conclusion: This study showed that workers highly exposed to both physical and psychosocial workplace risk factors were more likely to report symptoms of musculoskeletal disorders than workers highly exposed to one or the other. The results suggest an interaction between physical and psychosocial risk factors in the workplace that increased the risk of reporting symptoms in the upper limbs. Psychosocial risk factors at work were more important when exposure to physical risk factors at work were high than when physical exposure was low. Ergonomic intervention strategies that aim to minimise the risks of work related musculoskeletal disorders of the upper limb should not only focus on physical work factors but also psychosocial work factors.
\end{abstract}

C ritical reviews have shown that physical and psychosocial factors within the workplace are determinants of musculoskeletal disorders of the neck and upper cation appliing postures. Psychosocial risk factors at work have included intensified workload, time pressure, low job control, monotonous work, and low support from coworkers and management.

The contribution of psychosocial risk factors at work in the aetiology of musculoskeletal disorders of the back, neck, and upper limbs may be more important when the risk from exposure to physical work factors is low according to current, but limited, evidence. ${ }^{5}$ These limits include the study design of the contemporary epidemiological evidence. These have aimed at identifying the independent effects of each set of factors upon musculoskeletal disorders. However, physical and psychosocial work factors coexist and may potentially interact to increase risk. A recent epidemiological study on back disorders found that psychosocial risk factors at work increased risk when workers were highly exposed to physical risk factors at work- that is, an interaction effect between physical and psychosocial risk factors at work was found such that the relative excess risk from exposure to both sets of factors was greater than the sum of the relative excess risk from high exposure to only one set of factors (either physical or psychosocial). ${ }^{6}$ Potential interaction effects (between physical and psychosocial risk factors at work) and association with musculoskeletal disorders of the neck and upper limbs have not been satisfactorily investigated. Therefore, the aim of this study was to investigate the potential interactions between physical and psychosocial work related risk factors and symptoms of musculoskeletal disorders of the neck and upper limbs using an epidemiological approach. The potential existence of such interactions would have important implications for workplace ergonomics programmes aimed at reducing the risk of musculoskeletal disorders of the neck and upper limbs.

\section{MATERIAL AND METHODS}

The study design was cross sectional with a study population comprising 1514 male and female workers from 26 randomly selected sites of a United Kingdom company. Manual workers, delivery drivers, customer services queries and computer workers and general office staff completed a self administered questionnaire covering personal data and demographics, physical and psychosocial work factors, and musculoskeletal symptoms. The previously validated questionnaire items have been reported elsewhere. ${ }^{6}$ 
Data on job title, age, and sex were obtained for each worker in the study population from personnel records to compare survey respondents and non-respondents. The prevalence of disability due to musculoskeletal disorders of the neck and upper limbs was obtained from company medical severance data over a 5 year period to investigate any potential healthy worker effects. Ethical permission for the cross sectional epidemiological study was obtained from the University of Surrey committee on ethics.

\section{Exposure classification}

Each worker was classified for physical and psychosocial exposure. The four exposure groups were low physical exposure and low psychosocial exposure, low physical exposure and high psychosocial exposure, high physical exposure and low psychosocial exposure, and high physical exposure and high psychosocial exposure.

A worker could not be classified into more than one exposure group. Workers in the low physical and low psychosocial exposure group served as an internal reference population for the other three exposure groups.

Workers that did not satisfy the criteria for classification into low or high physical exposure were classified into an undefined physical exposure group with either low or high psychosocial exposure. The undefined group of workers had relatively high levels of physical exposure compared with the low physical exposure group but did not satisfy the criteria for high physical exposure. This group of workers was subject to the greatest degree of self reporting bias and could not be classified into a low or high physical exposure group as the true exposure classification was unclear. Self reported questionnaires used for collecting physical exposure data have restricted validity but are able to differentiate between low and high exposure groups. ${ }^{7}$ Therefore, this procedure was required to minimise self reporting bias that may result in exposure misclassification and underestimation of risk. ${ }^{8}$ Workers with only low and high physical exposures were used for comparison and workers classified into the undefined group were excluded from the analyses of risk.

The age, sex, years spent in their current job, and outcome characteristics of those workers in the undefined and the exposure classified groups were compared to determine any potential bias from excluding workers in the risk analyses.

The exposure criteria were predetermined from an established model ${ }^{9}$ and also from epidemiological studies providing a measure of risk for physical and psychosocial work factors. The derivation of the exposure criteria and questionnaire items used for exposure classification are described in detail elsewhere. ${ }^{6}$

Boolean algebraic expressions for the high and low physical exposure criteria were used.

\section{Boolean algebraic expression for high physical exposure criteria}

Criterion 1: lifting $\geqslant 16 \mathrm{~kg} \geqslant$ once/hour.

Criterion 2: lifting 6-15 kg $\geqslant$ once/hour and experiencing vibration while sitting $\geqslant$ half the working day.

An individual worker was classified as having high physical exposure if at least one of the criteria (criterion 1 or 2) were satisfied. Therefore, lifting greater than $16 \mathrm{~kg}$ more than or equal to once/hour would classify a worker as high physical exposure. A worker would also be classified as having high physical exposure if a 6-15 kg load was lifted more than or equal to once/hour and, additionally, vibration while sittingfor example, driving - was experienced for more than or equal to half the working day.
Boolean algebraic expression for low physical exposure criteria

Lifting 6-15 kg < once/hour, and experiencing vibration while sitting $\leqslant$ quarter of the working day, and lifting $\geqslant 16 \mathrm{~kg}$ not at all.

To be classified as having low physical exposure a worker had to satisfy all three statements. It was thought that the high and low exposure criteria were appropriate for classifying workers with exposure to risk factors for musculoskeletal disorders of the neck and upper limb for the following reasons.

The effects of manual handling upon musculoskeletal disorders of the neck and upper limbs were unclear and required further study. ${ }^{10}$ The few studies that have investigated lifting and musculoskeletal pain of the neck and upper limbs have shown an increased risk. ${ }^{11}{ }^{12}$ Work related musculoskeletal disorders of the neck and upper limbs in general have been associated with high force and high repetition, as well as vibration for some disorders. ${ }^{4}{ }^{13}$ A review by Ariëns et al $^{14}$ reported that there was a positive relation between self reported neck pain and hand-arm vibration after the criteria for inclusion of an article in the review were altered to include more studies. The criteria for high physical exposure comprise lifting that requires high force application and repetition at the hand due to lifting as well as the experience of whole body vibration. It is acknowledged that hand-arm vibration and whole body vibration may present different internal loads and primarily affect different body regions; however, whole body vibration was still considered a valid risk factor for musculoskeletal disorders of the neck and upper limbs. A study of occupational drivers also showed a positive relation between back, shoulder, and neck pain indicating that possibly any disorder may ensue if exposed to lifting and whole body vibration. ${ }^{15}$ An investigation of occupational salespeople who drive showed that the 12 month prevalence of neck pain was associated with annual driving distance, and the 12 month prevalence of shoulder pain was associated with the weekly time spent in a car. ${ }^{16}$ However, lifting heavy loads was not associated with back, neck, or shoulder pain in this study but this was probably due to low exposure to this risk factor in $95 \%$ of the salespeople. A review of the health effects of long term occupational exposure to whole body vibration cites several studies that have reported an increased frequency of subjective complaints among drivers of pain in the neck and shoulders. ${ }^{17}$

Criteria for psychosocial exposure was defined.

High psychosocial exposure criteria

High psychosocial exposure criteria were high mental demands, low job control, and low social support. At least two of these criteria for high psychosocial exposure had to be satisfied to be classified in this group.

\section{Low psychosocial exposure criteria}

Low psychosocial exposure criteria were low mental demands, high job control, and high social support. At least two of the criteria for low psychosocial exposure had to be satisfied to be classified in this group. These criteria were developed from the epidemiological literature on disorders of the neck, shoulder, upper limbs, and back. ${ }^{6}$

\section{Definition of outcomes}

Musculoskeletal symptoms in the neck, shoulders, elbows, and hands or wrists were defined by aches, pain, or discomfort during the 7 days preceding completion of the questionnaire. Musculoskeletal symptoms experienced in the upper limbs (shoulders, elbows, hands or wrists) irrespective of neck pain in the past 7 days were also used as an outcome measure.

Assessing self reported symptoms is important as these may lead to absence form work in the long term. This was shown in a 2 year follow up study in which workers that experienced symptoms in the neck, shoulder, and upper limbs 2 
Table 1 The number of subjects classified or unclassified into each exposure group

\begin{tabular}{lccc}
\hline & \multicolumn{2}{l}{ Psychosocial exposure } & \\
\cline { 2 - 3 } Physical exposure & Low & High & Totals \\
\hline High & 172 & 168 & 340 \\
Low & 115 & 109 & 224 \\
Subtotal classified & 287 & 277 & 564 \\
Unclassified & 58 & 98 & 156 \\
Totals & 345 & 375 & 720 \\
\hline
\end{tabular}

years before follow up were two to four times more likely to be off work at follow up (assessed from company records) than workers not experiencing symptoms. ${ }^{18}$

\section{Statistical analyses}

The association between exposure and self reported symptoms in the neck, hands or wrists, and upper limbs was assessed by Pearson's $\chi^{2}$ test for contingency tables. For a further assessment, unconditional multiple logistic regression was used to estimate the odds ratios (ORs) for these symptoms for each exposure group. Age, sex, and cumulative exposure (years spent in the present job) were adjusted for in the logistic regression model. For each symptom, non-significant covariates remained in the model because of the theoretical plausibility of the variables in determining the outcomes. An alternative logistical regression stepwise (backward unconditional) procedure was also used to examine modification effects for men only. The main models comprised age, years in the job, and three binary variables representing the exposure factors (physical and psychosocial, with low physical and low psychosocial exposure as the reference category). The full models also included first order interactions between confounders (age and years spent in the present job) and the exposure factors.

Variables for the exposure terms were coded 0 for low exposure and 1 for high exposure. Indicator terms for age were coded 0 for references (subject's age $\leqslant 40$ years) and 1 for subject's age $>40$ years.

Two binary indicator variables were used for the cumulative exposure variable with three strata $(<6$ years, $6-15$ years, and $>15$ years). Confidence intervals for the model covariates were calculated at the $95 \%$ level.

\section{Assessment of interactions}

Epidemiological interaction is present when the effect of one factor increases the effect of another factor. Such an interaction was investigated between physical and psychosocial workplace risk factors and was analysed with an additive risk model. ${ }^{19} 20$ The rationale for using an additive risk model is discussed elsewhere. ${ }^{6}$ To investigate interactions between these two sets of factors with logistical regression, participants who reported both high physical exposure and high psychosocial exposure were contrasted with participants who reported high exposure to only one of them. The odds of experiencing disorders in these exposure groups were divided by the odds in a group who were not highly exposed to either set of factors to produce ORs. For a potential interaction to exist $\left(\mathrm{R}_{11}-\mathrm{R}_{01}\right)-\left(\mathrm{R}_{10}-\mathrm{R}_{00}\right)$ must be greater than zero. The term $R_{11}$ represents the measure of risk (prevalence ratio or OR in this case) from high exposure to physical and psychosocial factors (the combined sets of factors), $\mathrm{R}_{10}$ represents the risk from exposure to high physical and low psychosocial factors (exposure to only the first set of factors), $R_{01}$ represents the risk from low physical and high psychosocial factors (exposure to only the second set of factors), and $\mathrm{R}_{00}$ represents the risk from exposure to low physical and low psychosocial factors (exposure to neither set of factors). The proportion of excess risk due to interaction was calculated from the results of the logistical regression analyses using indicator terms, $\left(\mathrm{R}_{11}-\mathrm{R}_{01}-\mathrm{R}_{10}+\mathrm{l}\right) / \mathrm{R}_{11}$ with corresponding $95 \%$ confidence intervals $(95 \% \mathrm{CIs}) .{ }^{21} \mathrm{~A}$ value greater than zero indicates a potential interaction effect.

\section{RESULTS}

\section{Study population characteristics}

Of the 1514 workers invited to participate in the survey, 891 workers returned the questionnaire (59\%). Twenty two respondents returned uncompleted or insufficiently completed questionnaires giving a survey response of $57 \%$. A higher response rate was obtained for office workers $(82 \%)$ than manual handlers (49\%), manual handling drivers (72\%), and technicians (42\%).

Of the 869 responses, 720 had provided the exposure and outcome data for classification. Table 1 shows the distribution of the 720 subjects within each exposure group. One hundred and fifty six workers were classified between low and high physical exposure in the undefined exposure group. These workers did not differ from the workers included in the risk analyses for age, years spent in the present job, or musculoskeletal outcomes. There was a significant difference across the two groups for $\operatorname{sex}\left(\chi^{2}=21.61, p<0.0001\right)$. About $80 \%$ of workers in the risk analyses were men compared with $96 \%$ in the undefined exposure group.

Sixty three per cent of workers in the undefined exposure group had high exposure to psychosocial risk factors.

The low physical and low psychosocial exposure group contained men who were older and had a greater number of years in the present job than did the other exposure groups (table 2 ). Men and women were not evenly distributed throughout the exposure groups. No women were classified in the high physical exposure groups. Women were slightly younger (median) in the low physical and low psychosocial exposure group and there was no difference in the years spent in the

Table 2 Sex, age, and years spent in the present job across exposure groups

\begin{tabular}{|c|c|c|c|c|}
\hline & \multicolumn{4}{|l|}{ Exposure } \\
\hline & $\begin{array}{l}\text { Low physical low } \\
\text { psychosocial }\end{array}$ & $\begin{array}{l}\text { Low physical high } \\
\text { psychosocial }\end{array}$ & $\begin{array}{l}\text { High physical low } \\
\text { psychosocial }\end{array}$ & $\begin{array}{l}\text { High physical high } \\
\text { psychosocial }\end{array}$ \\
\hline \multicolumn{5}{|l|}{ Subject $(n)$ : } \\
\hline Men & 60 & 50 & 172 & 168 \\
\hline Woman & 55 & 59 & 0 & 0 \\
\hline \multicolumn{5}{|c|}{ Age (y, median category (quartile range)): } \\
\hline Men & $46-50(36-55)$ & $36-40(26-45)$ & $36-40(31-50)$ & $36-40(31-50)$ \\
\hline Woman & $31-35(26-45)$ & $36-40(31-50)$ & - & - \\
\hline \multicolumn{5}{|c|}{ Duration in job (y, mean (SD)): } \\
\hline Men & $9.6(10.1)$ & $6.0(8.5)$ & $6.5(7.6)$ & $6.9(7.8)$ \\
\hline Woman & $7.0(9.0)$ & $6.8(9.1)$ & - & - \\
\hline
\end{tabular}


Table 3 Percentage of cases with symptoms for each exposure group

\begin{tabular}{|c|c|c|c|c|}
\hline \multirow[b]{2}{*}{ Region (\% pain in past 7 days) } & \multicolumn{4}{|l|}{ Exposure } \\
\hline & $\begin{array}{l}\text { Low physical, low } \\
\text { psychosocial (1) }\end{array}$ & $\begin{array}{l}\text { Low physical, high } \\
\text { psychosocial (2) }\end{array}$ & $\begin{array}{l}\text { High physical, low } \\
\text { psychosocial (3) }\end{array}$ & $\begin{array}{l}\text { High physical, high } \\
\text { psychosocial (4) }\end{array}$ \\
\hline \multicolumn{5}{|l|}{ Neck (34\%): } \\
\hline Yes (n) & 41 & 42 & 48 & 59 \\
\hline No $(n)$ & 74 & 67 & 124 & 109 \\
\hline Prevalence proportion & 0.357 & 0.385 & 0.279 & 0.351 \\
\hline \multicolumn{5}{|l|}{ Differences in proportions: } \\
\hline$(2)-(1)$ & 0.029 & & & \\
\hline (4)-(3) & 0.072 & & & \\
\hline$[(4)-(3)]-[(2)-(1)]$ & 0.043 & & & \\
\hline \multicolumn{5}{|l|}{ Shoulders (35\%): } \\
\hline Yes (n) & 39 & 34 & 57 & 69 \\
\hline No $(n)$ & 76 & 75 & 115 & 99 \\
\hline Prevalence proportion & 0.339 & 0.312 & 0.331 & 0.411 \\
\hline \multicolumn{5}{|l|}{ Differences in proportions: } \\
\hline$(2)-(1)$ & -0.027 & & & \\
\hline (4)-(3) & 0.079 & & & \\
\hline$[(4)-(3)]-[(2)-(1)]$ & 0.107 & & & \\
\hline \multicolumn{5}{|l|}{ Elbows (17\%): } \\
\hline Yes $(n)$ & 9 & 12 & 37 & 43 \\
\hline No $(n)$ & 106 & 97 & 135 & 125 \\
\hline Prevalence proportion & 0.078 & 0.110 & 0.215 & 0.256 \\
\hline \multicolumn{5}{|l|}{ Differences in proportions: } \\
\hline$(2)-(1)$ & 0.032 & & & \\
\hline (4)-(3) & 0.041 & & & \\
\hline$[(4)-(3)]-[(2)-(1)]$ & 0.009 & & & \\
\hline \multicolumn{5}{|l|}{ Hands/wrists (35\%): } \\
\hline Yes $(n)$ & 15 & 27 & 68 & 89 \\
\hline No $(n)$ & 100 & 82 & 104 & 79 \\
\hline Prevalence proportion & 0.130 & 0.248 & 0.395 & 0.530 \\
\hline \multicolumn{5}{|l|}{ Differences in proportions: } \\
\hline$(2)-(1)$ & 0.117 & & & \\
\hline (4)-(3) & 0.134 & & & \\
\hline$[(4)-(3)]-[(2)-(1)]$ & 0.017 & & & \\
\hline \multicolumn{5}{|l|}{ Upper limbs (55\%): } \\
\hline Yes (n) & 48 & 55 & 98 & 115 \\
\hline No $(n)$ & 67 & 54 & 74 & 53 \\
\hline Prevalence proportion & 0.417 & 0.505 & 0.570 & 0.685 \\
\hline \multicolumn{5}{|l|}{ Differences in proportions: } \\
\hline$(2)-(1)$ & 0.087 & & & \\
\hline (4)-(3) & 0.115 & & & \\
\hline$[(4)-(3)]-[(2)-(1)]$ & 0.028 & & & \\
\hline
\end{tabular}

present job for women in the low physical and low psychosocial or the low physical and high psychosocial exposure groups. Women and men performed sedentary office work but only men performed manual handling and delivery driving.

\section{Musculoskeletal disorders of the neck and upper limbs}

Table 3 shows that about one third of the study population reported symptoms of musculoskeletal disorder in the neck, shoulders, and hands or wrists in the previous 7 days. About $55 \%$ reported symptoms of musculoskeletal disorders of the upper limbs. The lowest prevalence was reported for elbow disorders $(17 \%)$.

Table 3 also shows the number of subjects (and the prevalence proportion ratios) who experienced musculoskeletal disorders for each exposure group. For the neck and shoulders, the prevalence proportions for all four exposure groups were similar $\left(\chi^{2}=4.071 ; \mathrm{df}=3, \mathrm{p}=0.254\right.$ for the neck and $\chi^{2}=3.704$; $\mathrm{df}=3, \mathrm{p}=0.295$ for the shoulders). For the elbow and upper limbs, the prevalence proportions of the high physical and low psychosocial or high physical and high psychosocial groups were significantly higher than those of the other two exposure groups $\left(\chi^{2}=19.573 ; \mathrm{df}=3, \mathrm{p}<0.001\right.$ and $\chi^{2}=21.492 ; \mathrm{df}=3$, $\mathrm{p}<0.001$ ); in particular the high physical and high psychosocial exposure group had the highest prevalence.

\section{Modelling}

Analyses were performed for the mixed male and female population and also for the data from men only to compare the ORs for each variable in the models.

\section{Mixed sex population}

Table 4 shows the ORs from the model for symptoms of neck disorders experienced in the past 7 days. None of the reported ORs had 95\% CIs greater than one.

Table 5 shows the ORs from the model for hand or wrist disorders in the previous 7 days for each exposure group compared with low physical and low psychosocial exposure. All three high exposure groups had significant ORs. High physical and high psychosocial exposure produced the highest OR (OR $7.5595 \%$ CI 3.76 to 15.16). An increased OR was also found for those aged $>40$, sex (men) and increasing years spent in the present job. Although sex and duration of employment did not have $95 \%$ CIs greater than one.

Table 6 shows the ORs from the model for symptoms in the upper limbs in the previous 7 days irrespective of neck pain. The highest OR was found for high physical and high psychosocial exposure (OR $3.7495 \%$ CI 2.12 to 6.60 ), followed by high physical and low psychosocial exposure (OR 2.28 95\% CI 1.31 to 3.98 ). Age $>40$ years and years spent in the present job 
Table 4 Models for neck disorder symptoms in the past 7 days

\begin{tabular}{|c|c|c|c|c|}
\hline \multirow[b]{2}{*}{ Factor: variable } & \multicolumn{2}{|c|}{ Mixed population model } & \multicolumn{2}{|c|}{ Male only population model } \\
\hline & OR & $(95 \% \mathrm{Cl})$ & OR & $(95 \% \mathrm{Cl})$ \\
\hline \multicolumn{5}{|l|}{ Sex: } \\
\hline Women & 1 & & & \\
\hline Men & 0.68 & 0.39 to 1.18 & & \\
\hline \multicolumn{5}{|l|}{ Age: } \\
\hline$\leqslant 40$ & 1 & & 1 & \\
\hline$>40$ & 1.49 & 0.99 to 2.23 & 1.69 & 1.05 to 2.74 \\
\hline \multicolumn{5}{|l|}{ Duration of the job $(y)$ : } \\
\hline$<6$ & 1 & & 1 & \\
\hline $6-15$ & 0.74 & 0.45 to 1.24 & 0.72 & 0.42 to 1.23 \\
\hline$>15$ & 0.79 & 0.47 to 1.34 & 0.69 & 0.37 to 1.23 \\
\hline Low physical, low psychosocial & 1 & & 1 & \\
\hline Low physical, high psychosocial & 1.10 & 0.64 to 1.91 & 1.19 & 0.53 to 2.67 \\
\hline High physical, low psychosocial & 0.91 & 0.51 to 1.64 & 0.96 & 0.50 to 1.86 \\
\hline High physical, high psychosocial & 1.25 & 0.70 to 2.22 & 1.31 & 0.69 to 2.50 \\
\hline
\end{tabular}

Table 5 Models for hand or wrist disorder symptoms in the past 7 days

\begin{tabular}{|c|c|c|c|c|}
\hline \multirow[b]{2}{*}{ Factor: variable } & \multicolumn{2}{|c|}{ Mixed population model } & \multicolumn{2}{|c|}{ Male only population model } \\
\hline & OR & $(95 \% \mathrm{Cl})$ & OR & $(95 \% \mathrm{Cl})$ \\
\hline \multicolumn{5}{|l|}{ Sex: } \\
\hline Women & 1 & & & \\
\hline Men & 1.18 & 0.59 to 2.35 & & \\
\hline \multicolumn{5}{|l|}{ Age: } \\
\hline$\leqslant 40$ & 1 & & 1 & \\
\hline$>40$ & 1.55 & 1.01 to 2.37 & 1.69 & 1.04 to 2.74 \\
\hline \multicolumn{5}{|l|}{ Duration of the job $(y)$ : } \\
\hline$<6$ & 1 & & 1 & \\
\hline $6-15$ & 1.17 & 0.71 to 1.92 & 1.27 & 0.76 to 2.13 \\
\hline$>15$ & 1.11 & 0.64 to 1.95 & 1.19 & 0.63 to 2.26 \\
\hline Low physical, low psychosocial & 1 & & 1 & \\
\hline Low physical, high psychosocial & 2.32 & 1.15 to 4.70 & 2.99 & 1.12 to 7.96 \\
\hline High physical, low psychosocial & 4.42 & 2.20 to 8.90 & 5.22 & 2.28 to 11.92 \\
\hline High physical, high psychosocial & 7.55 & 3.76 to 15.16 & 8.93 & 3.91 to 20.36 \\
\hline
\end{tabular}

Table 6 Models for symptoms in the upper limbs (shoulder, elbow, hand or wrist) in the past 7 days irrespective of neck pain

\begin{tabular}{|c|c|c|c|c|}
\hline \multirow[b]{2}{*}{ Factor:variable } & \multicolumn{2}{|c|}{ Mixed population model } & \multicolumn{2}{|c|}{ Male only population model } \\
\hline & OR & $(95 \% \mathrm{Cl})$ & OR & $(95 \% \mathrm{Cl})$ \\
\hline \multicolumn{5}{|l|}{ Sex: } \\
\hline Women & 1 & & & \\
\hline Men & 0.75 & 0.44 to 1.28 & & \\
\hline \multicolumn{5}{|l|}{ Age: } \\
\hline$\leqslant 40$ & 1 & & 1 & \\
\hline$>40$ & 1.28 & 0.86 to 1.90 & 1.49 & 0.93 to 2.39 \\
\hline \multicolumn{5}{|l|}{ Duration of the job $(y)$ : } \\
\hline$<6$ & 1 & & 1 & \\
\hline $6-15$ & 1.25 & 0.77 to 2.02 & 1.35 & 0.81 to 2.27 \\
\hline$>15$ & 1.52 & 0.90 to 2.55 & 1.32 & 0.70 to 2.48 \\
\hline Low physical, low psychosocial & 1 & & 1 & \\
\hline Low physical, high psychosocial & 1.46 & 0.86 to 2.49 & 1.48 & 0.68 to 3.21 \\
\hline High physical, low psychosocial & 2.28 & 1.31 to 3.98 & 2.34 & 1.26 to 1.37 \\
\hline High physical, high psychosocial & 3.74 & 2.12 to 6.60 & 3.82 & 2.03 to 7.20 \\
\hline
\end{tabular}

did have increased ORs but they were not significantly different from one.

\section{Male population only}

From tables 4-6, the ORs and 95\% CIs for each variable in the men only population were very similar to the OR and $95 \%$ CIs for the same variable in the mixed population. In these analyses, the logistic regression model included interaction terms between the confounders (age and years spent in the present job) and the three binary exposure factors. When fitting this full model, in all regressions the correlation coefficients between estimates of main and interaction effects were large indicating multicollinearity. This was further confirmed by the application of stepwise (backward) logistic 
Table 7 Proportions due to interactions for neck, hand or wrist, and upper limb disorder symptoms in the male only population

\begin{tabular}{lll}
\hline & \multicolumn{2}{l}{ Male only population } \\
\cline { 2 - 3 } & $\begin{array}{l}\text { Proportion of } \\
\text { excess risk }\end{array}$ & $95 \% \mathrm{Cl}$ \\
\hline Neck disorder symptoms & 0.12 & -0.65 to 0.90 \\
$\begin{array}{l}\text { Hand or wrist disorder symptoms } \\
\text { Upper limb disorder symptoms }\end{array}$ & 0.19 & -0.19 to 0.57 \\
irrespective of neck pain & 0.26 & -0.14 to 0.66 \\
\hline
\end{tabular}

regression. In all cases, the deletion of all interactions was deemed as non-significant by the log likelihood test. The results for the male population only shown in tables 4-6 show the reduced models.

\section{Interactions}

In table 3 , the positive differences shown for $((4)-(3))-((2)-(1))$ in the proportion estimates indicated a potential interaction effect between physical and psychosocial workplace risk factors for each body region.

Table 7 shows the proportion of excess risk calculated from the adjusted ORs from the logistic regressions for each region with data for men only. Although each proportion was greater than zero, indicating an interaction, the result was not significant at the $95 \%$ level. The highest value was found for symptoms in the upper limbs irrespective of neck pain.

\section{DISCUSSION}

\section{Neck disorders}

A tentative increase in the OR for neck disorders was found for the high physical and high psychosocial exposure group. A previous cross sectional study investigated the combined effects of physical and psychosocial exposure for neck pain defined as requiring medical attention in the previous year. ${ }^{12}$ Although this study did not explore interaction effects it did show that combined exposure to heavy lifting and poor psychosocial environment (work content, social support, and perceived workload) increased the risk of neck pain compared with exposure to neither.

In our study, the prevalence proportion for neck disorders in the 7 days before completion of the questionnaire was about $36 / 100$ workers in the low physical and low psychosocial exposure group. This suggests that risk factors other than those used in the exposure criteria and other background risks may have been present and would account for the high prevalence in the internal reference group. Therefore, the criteria used to classify subjects into exposure groups may not have been sufficiently sensitive to detect an increased risk of symptoms of neck disorders.

About $88 \%$ of subjects were office workers in the low physical and low psychosocial exposure group. Of the 869 workers in the study population about $95 \%$ of office workers used a keyboard and $80 \%$ of office workers sat using a keyboard for more than three quarters of the day. Most were in a customer service centre and answered customer queries by telephone. There were few opportunities to take breaks and change from a seated working posture.

According to some reviews there is strong evidence to support static or maintained postures as a risk factor for musculoskeletal disorders of the neck and shoulders. ${ }^{42} \mathrm{~A}$ recent review also concluded that there was evidence for a positive relation between the duration of a fixed sedentary posture in the workplace and self reported neck pain, ${ }^{14}$ and several studies have shown an increased risk of neck disorders in office workers. ${ }^{23-26}$ Neck symptoms were found to be the most often reported musculoskeletal problem for office workers and risk factors for neck disorders included using a telephone for 4-6 hours compared with 0-2 hours a day (OR 1.4). ${ }^{27}$ Another study reported a percentage of $61.5 \%$ for neck or shoulder discomfort experienced in the past 12 months in office computer workers and found an increased risk of neck or shoulder complaints due to limited opportunities for rest breaks and static work postures. ${ }^{28}$ A high percentage of neck pain in the past 7 days (about 30\%) and in the past year (63\%) for office workers using computers or typewriters has also been shown. ${ }^{29}$ Working with this type of equipment for 5 hours or more increased the risk of neck pain (OR 1.65 95\%CI 1.02 to 2.67 ).

Therefore in our study, it is likely that a seated static work posture and working with computers for more than three quarters of the working day resulted in symptoms of disorders of the neck in the internal reference population.

\section{Upper limb disorders}

Workers highly exposed to both physical and psychosocial risk factors at work had the highest likelihood of reporting symptoms of disorders in the upper limbs and specifically symptoms of disorders of the hands or wrists compared with workers in the other exposure groups. Findings that frequent lifting tasks (median 16-45 kg lifted more than 30 times/ hour) typically performed by workers in this exposure group identified the application of high force exertion at the hand..$^{30}$ Other researchers have shown that handling tasks of this nature require about $30 \%$ of handgrip maximum voluntary contraction. ${ }^{31}$ Lifting often occurs in combination with awkward and dynamic wrist postures and this may account for the high number of reports of discomfort in the hands and wrists in workers performing lifting tasks. ${ }^{30} 32$

One epidemiological study of wrist disorders reported an increase in risk when exposed to a combination of high force and high repetition that was greater than being exposed to force or repetition alone (a multiplicative interaction was found) ${ }^{33}$ This relation has also been found in an experimental study that replicated the exposure categories used in the epidemiological study. ${ }^{34}$ It was also concluded from the epidemiological study that the force exerted was more important than repetitiveness. Another cross sectional study supported this conclusion and added that the force exerted at the hand had a strong influence on the velocity of movement, the angular repetition at the hands or wrists, and the degree of movement in flexion and extension. ${ }^{35}$ Wrist motion, angular velocity, and acceleration have significantly differentiated low and high risk groups with musculoskeletal disorders of the hands or wrists. $^{36}$

Exposure to risk factors for the hands or wrists in tasks requiring work at a visual display unit also involves the application of force in several postures as well as repetitive movements of the hands or wrists. ${ }^{35}{ }^{37}$ However, the levels of exposure particularly to the force exerted at the hand may be relatively lower compared with frequent lifting tasks. ${ }^{38}{ }^{39}$ This may explain the differences in risk between those in the high physically exposed groups and those in the low physically exposed groups.

Workers who reported low physical exposure and high psychosocial exposure were more likely to experience symptoms of disorders of the hands or wrists than those with low exposure to both sets of factors. Therefore, exposure to a combination of psychosocial risk factors at work may significantly contribute to the reporting of symptoms. Three studies conducted by the National Institute of Occupational Safety and Health (NIOSH) of the United States in office workers who used computers have also shown an association between psychosocial work factors and musculoskeletal disorders of the upper limbs. ${ }^{40}$ The association between psychosocial risk factors at work such as job demands, decision latitude, and 
social support and musculoskeletal symptoms in the upper limbs has not been widely researched in office workers and contradictory evidence exists. ${ }^{26} 4142$ One study showed that these psychosocial factors were not associated with symptoms of musculoskeletal disorders of the upper limbs, but organisational and psychological factors were important, for example, possibility of job loss, overcrowding, and work stress. ${ }^{41}$

\section{Interactions}

Potential interactions between physical and psychosocial risk factors at work were present as indicated by a departure from an additive model of risk. Male workers highly exposed to both sets of physical and psychosocial risk factors at work experienced the biological effects of background exposure, high physical exposure, high psychosocial exposure, and the interaction effects of these two factors. Deviations from an additive risk model should be used to measure interaction between determinants that are public health concerns. ${ }^{19}{ }^{43} 44$

To our knowledge no other study has investigated the potential interaction effects between physical and psychosocial work factors on the risks of work related musculoskeletal disorders of the neck and upper limbs. An explanation for the interaction effects between physical and psychosocial risk factors at work has been described in a previous paper by the same authors. ${ }^{6}$ The contemporary evidence suggests that psychosocial work factors may be important determinants for symptoms in the hands or wrists when exposure to physical risk factors at work is low $w^{5}$ and this view is supported by the results in this study. However, this study also showed that psychosocial work factors are important in the presence of high exposure to physical risk factors at work. The difference in the prevalence between the high physical and high psychosocial and the high physical and low psychosocial exposure groups was greater than the difference between the low physical and high psychosocial and the low physical and low psychosocial exposure groups for each region (table 3 ). It is plausible that psychosocial risk factors at work may influence exposure to tasks requiring heavy and frequent lifting as well as tasks involving computers. For example, performing lifting tasks or computer work under time pressure may increase the lifting rate and typing speed respectively and also the force exerted for these tasks. Hence, the biomechanical load on the upper limbs would be increased. Low job control over schedules for work and rest may influence recovery of the musculoskeletal system. Poor social support from coworkers and managers may negatively influence work behaviour through frustration or anxiety that results in increased risk or it may affect the reporting of musculoskeletal symptoms. These examples would explain the influence of high psychosocial exposure on the low and high physical exposure groups. Psychosocial factors resulting in worker strain have been clearly associated with neck and upper limb complaints in tasks requiring high exposure and relatively low exposure to physical risk factors at work for upper limb disorders in a previous study. ${ }^{45}$ Questionnaire data from a study in The Netherlands of 36756 male employees and 7730 female employees have shown that jobs with mentally and physically demanding work are associated with greater musculoskeletal complaints in the neck and upper extremities than jobs requiring only high mental demands. ${ }^{46}$

\section{Response rates}

Although it seems that the participation rate varied between sedentary and manual handling and driving jobs, the percentage responses are, nevertheless, large enough to allow valid comparisons. The response rates achieved in this study are comparable with those of other studies investigating similar occupational groups. ${ }^{23} 293247-49$

\section{Exposure criteria}

Predetermined exposure criteria were used for classification of individual cases into low and high physical and psychosocial exposure groups. Combinations of long term whole body vibration and frequent lifting have produced the highest risks for low back pain, neck pain, and shoulder pain compared with the risks associated with individual factors. ${ }^{15}$ Combinations of high psychological demands, low decision latitude, and low social support may also result in the greatest risks compared with individual factors. ${ }^{50}$ The use of these criteria was appropriate for investigating musculoskeletal disorders of the upper limbs, however, more specific exposure criteria may be required for the neck.

For physical exposure in this study, 156 subjects did not satisfy the criteria for low or high physical exposure classification. The contrast between low and high physical exposure was required to reduce the potential effects of misclassification of exposure. ${ }^{51}$ The exclusion of subjects did not affect the overall distribution of age, years on the job, and musculoskeletal outcomes.

Research has shown that it is difficult for workers to accurately determine wrist postures, hand forces, and repetition rates. ${ }^{52}$ Therefore, it was considered more appropriate to use lifting rates and loads as surrogate measures of exposure to these factors when classifying workers into low and high physical exposure groups. Studies on occupational drivers have shown that whole body vibration may be associated with neck and shoulder complaints. ${ }^{15}{ }^{16}$ Therefore, it was reasonable to assess the duration of exposure of this factor by questionnaire. Objective workplace measurement of factorssuch as working with arms above shoulder height, pushing and pulling, or exertion of static hand forces-would have been required to enable classification of these aspects of physical exposure. Although the omission of these variables in the study is a possible weakness, the use of self report data for measuring these variables is known to be unreliable. ${ }^{534}$

Applying this methodology requires a large study population to provide sufficient study power, especially for studying interactions. ${ }^{55}$ Sufficient numbers were classified into each exposure group to detect a significant difference between exposure groups if such an effect existed while minimising the effect of a type I error.

\section{Measures of risk}

The OR was reported in this study and is an appropriate measure for estimating the likelihood of an association between exposure and outcome in cross sectional studies. ${ }^{56} 57$ However, one disadvantage of the OR is that it becomes an increasingly poor estimate of relative risk as the outcome prevalence increases. ${ }^{58}$ Thus, it should not be assumed that the ORs reported in this study are an accurate measure of the relative risk.

\section{Validity of exposure assessment}

The self reported items of physical exposure used to classify subjects into exposure groups had good validity when compared with instrumentation and observational measurements. The self reported psychosocial exposure items used to classify subjects into exposure groups had acceptable sensitivity and specificity when compared with a questionnaire assisted interview. ${ }^{6}$

The cross sectional study design allowed the relation between exposure and disease to be examined for people at the same time. Therefore with such a study design, it was not possible to determine whether the exposure was an antecedent of the outcome. ${ }^{589}$ It has been hypothesised that the experience of work related musculoskeletal disorders may also affect physical or psychosocial exposure.$^{60}$ For example, workers with disorders may change to jobs (within the same organisation) with less exposure to physical or psychosocial risk factors or may alter the way they perform their work task to reduce physical exposure. Similarly, perceptions of the way the work is organised may increase psychosocial exposure. 
Assuming the hypothesis is correct, the interactions found may only exist after symptoms of a disorder have developed. A prospective study design is required to test this hypothesis.

Risk may be underestimated or overestimated in epidemiological studies where subjects rate both exposure and outcomes at the same point in time. ${ }^{58}$ For example, subjects with pain may have high arousal levels or alertness to factors they think influence their pain, therefore, they may overestimate the amount of exposure to these factors. However, one study concluded that there was no support for the hypothesis that relative risk estimates were biased from rating behaviour where both exposure and outcomes were measured by subjects. ${ }^{61}$ This conclusion is supported by other studies. ${ }^{6}$

\section{Healthy worker effects}

Analysis of medical severance data for work related musculoskeletal disorders showed that only a small proportion of workers had left because of musculoskeletal disorders of the neck and upper limbs, therefore, there was a minimal healthy worker selection bias for this outcome in the total study population. These data could not be disclosed for reasons of confidentiality. Adjustment could not be made for workers who had resigned or who had left their employment because of musculoskeletal disorders of the neck and upper limbs but had not received medical severance. The survivor population tended to be younger and have less years spent in the present job. Age has been shown to increase the risk of neck or shoulder disorders in some studies. ${ }^{11} 2729326263$ The number of years in the job has also been shown to increase the risk of shoulder disorders. ${ }^{3}$ Therefore, the survivor population might be a healthier population. Despite this, being over 40 years old increased the risk of disorders of the neck and hands or wrists for most of the outcome measures. Age was not a risk factor for the upper limb disorder outcomes. Evidence from other studies showing age as a risk factor for upper limb disorders has not been consistent.

The average measures for the number of years spent in the present job and age were higher in the low physical and low psychosocial exposure reference group. This may have increased the prevalence of musculoskeletal symptoms in the internal reference group, which would have reduced the ORs for the other exposure groups. Workers could not move from heavy physical jobs to lighter physical jobs or vice versa in this study population so the risk estimates could not have been underestimated for this reason.

Women were not present in the high physical exposure groups because they did not perform work that required heavy and frequent lifting of the magnitude used for the high physical exposure criteria. It is commonly thought that women are more at risk of musculoskeletal disorders of the neck and upper limbs. However, there is evidence that the difference in risk is due to the differences in exposure to risk factors in the workplace rather than any constitutional factors. ${ }^{5}$ Including women in the low physical exposure groups did not bias the results according to the comparison of the ORs between the mixed sex population and the men only population for the low physical and high psychosocial exposure group. The OR for this exposure group was smaller for the mixed population than the men only population.

The age and sex distribution of the total study population had a similar distribution to the survey response population. Therefore, a response bias due to age and sex differences between the response and non-response population was unlikely. Response bias due to outcome or years spent at the job could not be assessed.

\section{CONCLUSIONS}

Exposure to physical workplace risk factors has been found to increase the risk of symptoms of musculoskeletal disorders of the hands or wrists but not the neck. Exposure to psychosocial workplace risk factors may increase risk of symptoms of musculoskeletal disorder of the hands or wrists even when there is low exposure to physical workplace risk factors. This study suggests that the risk of experiencing symptoms of disorders of the upper limbs is greatest when highly exposed to both psychosocial and physical workplace risk factors.

Physical and psychosocial risk factors at work may potentially interact to further increase the risk of symptoms of musculoskeletal disorders of the hands or wrists and upper limbs. Strategies aimed at the prevention of these work related musculoskeletal disorders should reduce exposure to physical and psychosocial workplace risk factors.

Prospective epidemiological studies concerned with work related musculoskeletal disorders are needed to confirm the presence of the interactions found here between physical and psychosocial workplace risk factors. More sensitive criteria for classifying exposure may be required to identify the presence or absence of interactions with neck symptoms.

\section{Authors' affiliations}

J J Devereux, P W Buckle, Robens Centre for Health Ergonomics, European Institute of Health and Medical Sciences, University of Surrey, Guildford, Surrey GU2 7TE, UK

I G Vlachonikolis, Medical Statistics Unit, European Institute of Health and Medical Sciences, University of Surrey, Guildford, Surrey GU2 7TE, UK

\section{REFERENCES}

1 Winkel J, Westgaard $\mathrm{RH}$. Occupational and individual risk factors for shoulder-neck complaints: Part II.The scientific basis (literature review) for the guide. International Journal of Industrial Ergonomics 1992:10:85-104.

2 Hagberg $M$, Silverstein BA, Wells RV, et al. Work related musculoskeletal disorders: a reference for prevention. London: Taylor and Francis, 1995:28-137.

3 Hales TR, Bernard BP. Epidemiology of work-related musculoskeletal disorders. Orthop Clin North Am 1996:27:679-709.

4 National Institute for Occupational Safety and Health. Musculoskeletal disorders and workplace factors: a critical review of epidemiologic evidence for work-related musculoskeletal disorders of the neck, upper extremity, and low back. Cincinnati, Ohio: DHHS (NIOSH) 1997:2.1-5c.31. (Publication No. 97-141.)

5 Buckle P, Devereux J. Work-related neck and upper limb musculoskeletal disorders. Bilbao, Spain: European Agency for Safety and Health at Work, 1999:39-42

6 Devereux JJ, Buckle PW, Vlachonikolis IG. Interactions between physical and psychosocial work risk factors increase the risk of back disorders: an epidemiological study. Occup Environ Med 1999:56:343-53.

7 Devereux JJ. A study of interactions between work risk factors and work related musculoskeletal disorders [dissertation]. University of Surrey, Guildford, Surrey, 1997:106-11.

8 Stewart PA, Herrick RF, Blair A, et al. Highlights of the 1990 Leesburg, Virginia, international workshop on retrospective exposure assessment for occupational epidemiology studies. Scand J Work Environ Health $1991 ; 17: 281-5$.

9 Armstrong TJ, Buckle P, Fine $\mathrm{L}$, et al. A conceptual model for work-related neck and upper-limb musculoskeletal disorders. Scand Work Environ Health 1993;19:73-84.

10 Hagberg M. Neck and arm disorders. BM 1996;313:419-22.

11 Holmstrom EB, Lindell J, Moritz U. Low back and neck/shoulder pain in construction workers: occupational workload and psychosocial risk factors: Part 2: Relationships to neck and shoulder pain. Spine 1992;17:672-7.

12 Linton SJ. Risk factors for neck and back pain in a working population in Sweden. Work Stress 1990;4:41-9.

13 Stenlund B. Osteoarthrosis of the acromioclavicular joint and shoulder tendinitis and their relation to occupational factors and sport [dissertation]. Solna, Sweden: National Institute of Occupational Health, 1992:3-32.

14 Ariëns GAM, Van Mechelen W, Bongers PM, et al. Physical risk factors for neck pain. Scand J Work Environ Health 2000;26:7-19.

15 Magnusson $\mathbf{M}$, Pope MH, Wilder DG, et al. Are occupational drivers at an increased risk for developing musculoskeletal disorders. Spine 1996;21:710-17

16 Skov T, Vilhelm B, Ørhede E. Psychosocial and physical risk factors for musculoskeletal disorders of the neck, shoulders, and lower back in salespeople. Occup Environ Med 1996;53:351-6.

17 Wickström B-O, Kjellberg A, Landström U. Health effects of long-term occupational exposure to whole-body vibration: a review. International Journal of Industrial Ergonomics 1994;14:273-92.

18 Burdorf A, Naaktgeboren B, Post W. Prognostic factors for musculoskeletal sickness absense and return to work among welders and metal workers. Occup Environ Med 1998;55:490-5. 
19 Rothman KJ. Modern epidemiology. Boston: Little, Brown, 1986.

20 Walker AM. Proportion of disease attributable to the combined effect of two factors. Int J Epidemiol 1981;10:81-5.

21 Hallquist J, Ahlbom A, Diderichsen F, et al. How to evaluate interaction between causes: a review of practices in cardiovascular epidemiology. $J$ Intern Med 1996:239:177-382.

22 Grieco A, Molteni G, De Vito G, et al. Epidemiology of musculoskeletal disorders due to biomechanical overload. Ergonomics 1998;41:1253-60.

23 Bergqvist $U$, Wolgast $E$, Nilsson B, et al. The influence of VDT work on musculoskeletal disorders. Ergonomics 1995;38:754-62.

24 Bernard BP, Sauter SL, Fine L, et al. Psychosocial and work organisation risk factors for cumulative trauma disorders in the hands and wrists of newspaper employees. Scand J Work Environ Health 1992;18(suppl 2): 1 19-20.

25 Hales TR, Sauter SL, Peterson MR, et al. Musculoskeletal disorders among visual display terminal users in a telecommunications company. Ergonomics 1994;37:1603-21

26 Polanyi MF, Cole DC, Beaton DE, et al. Upper limb work-related musculoskeletal disorders among newspaper employees: cross-sectional survey results. Am J Ind Med 1997;32:620-8.

27 Bernard BP, Sauter SL, Fine L, et al. Job task and psychosocial risk factors for work-related musculoskeletal disorders among newspaper employees. Scand J Work Environ Health 1994;20:417-26.

28 Bergqvist U, Wolgast E, Nilsson B, et al. Musculoskeletal disorders among visual display terminal workers: individual, ergonomic, and work organizational factors. Ergonomics 1995;38:763-76.

29 Kamwendo K, Linton SJ, Moritz U. Neck and shoulder disorders in medical secretaries: Part I: Pain prevalence and risk factors. Scand J Rehabil Med 1991;23:127-33.

30 Devereux JJ, Buckle P, Haisman MF. The evaluation of a hand-handle interface tool (HHIT) for reducing musculoskeletal discomfort associated with the manual handling of gas cylinders. International Journal of Industrial Ergonomics 1998;21:23-34.

31 Westerling D, Kilbom $\AA$. Physical strain in the handling of gas cylinders. Ergonomics 1981;24:623-32.

32 Van der Beek AJ, Frings-Dresen MHW, Van Dijk FJH, et al. Loading and unloading by lorry drivers and musculoskeletal complaints. International Journal of Industrial Ergonomics 1993;12:13-24.

33 Silverstein BA, Fine $L$, Armstrong TJ. Hand wrist cumulative trauma disorders in industry. Br J Ind Med 1986;43:779-84.

34 Moore A, Wells RV, Ranney D. Quantifying exposure in occupational manual handling tasks with cumulative trauma disorder potential. Ergonomics 1991;34:1433-53.

35 Malchaire J, Cock N, Robert AR. Prevalence of musculoskeletal disorders at the wrist as a function of angles, forces, repetitiveness and movement velocities. Scand J Work Environ Health 1996;22:176-81.

36 Marras WS, Schoenmarklin RW. Wrist motions in industry. Ergonomics 1993:36:341-51.

37 Karlqvist L, Bernmark E, Ekenvall L, et al. Computer mouse position as a determinant of posture, muscular load and perceived exertion. Scand J Work Environ Health 1998;24:62-73

38 Gerard MJ, Armstrong TJ, Foulke JA, et al. Effects of key stiffness on force and the development of fatigue while typing. Am Ind Hyg Assoc J 1996:57:849-54.

39 Rempel D, Serina E, Klinenberg E, et al. The effect of keyboard keyswitch make force on applied force and finger flexor muscle activity. Ergonomics 1997;40:800-8.

40 Hurrell JJJ, Bernard BP, Hales TR, et al. Psychosocial factors and musculoskeletal disorders: summary and implications of three Niosh health hazard evaluations of video display terminal work. In: Moon SD, Sauter SL, eds. Beyond biomechanics: psychosocial aspects of musculoskeletal disorders in office work. London: Taylor and Francis, 1996:99-105.
41 Marcus M, Gerr F. Upper extremity musculoskeletal symptoms among female office workers: associations with video display terminal use and occupational psychosocial stressors. Am J Ind Med 1996;29:161-70.

42 Ryan GA, Bampton M. Comparison of data process operators with and without upper limb symptoms. Community Health Study 1988;12:63-8.

43 Kleinbaum DG, Kupper LL, Morgenstern H. Epidemiologic research: principles and quantitative methods. New York: Van Nostrand Reinhold, 1982:403-18.

44 Koopman JS. Interaction between discrete causes. Am J Epidemiol $1981 ; 113: 716-24$

45 Ohlsson K, Hansson GA, Balogh I, et al. Disorders of the neck and upper limbs in woman in the fish processing industry. Occup Environ Med 1994:51:826-32.

46 de Zwart BCH, Broersen J, Frings-Dresen MHW, et al. Musculoskeletal complaints in the Netherlands in relation to age, gender and physically demanding work. Int Arch Occup Environ Health 1997;70:352-60.

47 Bovenzi $M$, Zadini A. Self-reported low back symptoms in urban bus drivers exposed to whole-body vibration. Spine 1992;17:1048-59.

48 Hedberg GE. The period prevalence of musculoskeletal complaints among Swedish professional drivers. Scand J Soc Med 1988;16:5-13.

49 Riihimäki H, Tola S, Videman T, et al. Low back pain and occupation: a cross-sectional questionnaire study of men in machine operating, dynamic physical work, and sedentary work. Spine 1989;14:204-9.

50 Karasek RA, Theorell T. Healthy work: stress, productivity, and the reconstruction of working life. New York: Basic Books, 1990:31-82.

51 Hernberg S. Introduction to occupational epidemiology. Michigan: Lewis, 1992:219.

52 Li G, Buckle P. Evaluating change in exposure to risk for musculoskeletal disorders a practical tool. Sheffield, U.K. Health and Safety Executive 1999:44-8. (Contract Research Report 251.)

53 Viikari-Juntura E, Rauas S, Martikainen R, et al. Validity of self-reported physical work load in epidemiologic studies on musculoskeletal disorders. Scand J Work Environ Health 1996;22:251-9.

54 Wiktorin C, Karlqvist L, Winkel J. Validity of self-reported exposures to work postures and manual materials handling. Scand J Work Environ Health 1993;19:208-14.

55 Gail MH. A bibliography and comments on the use of statistical models in epidemiology in the 1980s. Stat Med 1991;10:1819-95.

56 Lee J. Odds ratio or relative risk for cross-sectional data? Int J Epidemio 1994;23.

57 Strömberg U. Prevalence odds ratios v prevalence ratio. Occup Environ Med 1994:51:143-4.

58 Checkoway H, Pearce NE, Crawford-Brown DJ. Research methods in occupational epidemiology. Oxford: Oxford University Press, 1989:226-7.

59 Sorock GS, Courtney TK. Epidemiologic concerns for ergonomists: illustrations from the musculoskeletal disorder literature. Ergonomics 1996;39:562-78

60 Devereux JJ, Buckle PW. The impact of work organisation design and management practices upon work related musculoskeletal disorder symptomology. In: Vink P, Koningsveld EAP, Dhondt S, eds. Human factors in organizational design and management - VI. Amsterdam: North-Holland, 1998:275-9.

61 Toomingas A, Alfredsson L, Kilbom A. Possible bias from rating behavior when subjects rate both exposure and outcome. Scand J Work Environ Health 1997;23:370-7.

62 Tola S, Riihimäki H, Videman T, et al. Neck and shoulder symptoms among men in machine operating, dynamic physical work and sedentary work. Scand J Work Environ Health 1988;14:299-305.

63 Torp S, Riise T, Moen BE. Work-related musculoskeletal symptoms among car mechanics: a descriptive study. Occup Med 1996:46:407-13. 